\title{
The Dynamics of Microcystis Genotypes and Microcystin Production and Associations with Environmental Factors during Blooms in Lake Chaohu, China
}

\section{Li Yu ${ }^{1,2}$, Fanxiang Kong ${ }^{1, *}$, Min Zhang ${ }^{1}$, Zhen Yang ${ }^{1}$, Xiaoli Shi ${ }^{1}$ and Mingyong Du ${ }^{1}$}

1 State Key Laboratory of Lake Science and Environment, Nanjing Institute of Geography and Limnology, Chinese Academy of Sciences, Nanjing 210008, China; E-Mails: yuli514605@163.com (L.Y.); mzhang@niglas.ac.cn (M.Z.); zhyang@niglas.ac.cn (Z.Y.); xlshi@niglas.ac.cn (X.S.); dmy19890208@163.com (M.D.)

2 College of Resources and Environment, University of Chinese Academy of Sciences, Beijing 100049, China

* Author to whom correspondence should be addressed; E-Mail: fxkong@niglas.ac.cn; Tel./Fax: +86-25-5771-4759.

External Editor: Luis M. Botana

Received: 26 September 2014; in revised form: 7 November 2014 / Accepted: 24 November 2014 / Published: 2 December 2014

Abstract: Lake Chaohu, which is a large, shallow, hypertrophic freshwater lake in southeastern China, has been experiencing lake-wide toxic Microcystis blooms in recent decades. To illuminate the relationships between microcystin (MC) production, the genotypic composition of the Microcystis community and environmental factors, water samples and associated environmental data were collected from June to October 2012 within Lake Chaohu. The Microcystis genotypes and MC concentrations were quantified using quantitative real-time PCR (qPCR) and HPLC, respectively. The results showed that the abundances of Microcystis genotypes and MC concentrations varied on spatial and temporal scales. Microcystis exists as a mixed population of toxic and non-toxic genotypes, and the proportion of toxic Microcystis genotypes ranged from $9.43 \%$ to $87.98 \%$. Both Pearson correlation and stepwise multiple regressions demonstrated that throughout the entire lake, the abundances of total and toxic Microcystis and MC concentrations showed significant positive correlation with the total phosphorus and water temperature, suggesting that increases in temperature together with the phosphorus concentrations may promote more frequent toxic Microcystis blooms and higher concentrations of MC. 
Whereas, dissolved inorganic carbon (DIC) was negatively correlated with the abundances of total and toxic Microcystis and MC concentrations, indicating that rising DIC concentrations may suppress toxic Microcystis abundance and reduce the $\mathrm{MC}$ concentrations in the future. Therefore, our results highlight the fact that future eutrophication and global climate change can affect the dynamics of toxic Microcystis blooms and hence change the MC levels in freshwater.

Keywords: Microcystis; microcystin; 16S rDNA; mcyD; qPCR; environmental factors; Lake Chaohu

\section{Introduction}

Harmful cyanobacterial blooms pose a threat to freshwater ecosystems used for recreation and drinking water supply because cyanobacteria can synthesise toxic secondary metabolites, such as cyanotoxins [1-3]. Microcystins (MCs) are the most widespread cyanotoxins present in freshwater and act as a protein phosphatase inhibitors and tumour promoters, causing acute and chronic poisoning in humans and animals, particularly liver injury [4-7]. MCs are produced by diverse cyanobacterial genera, including Microcystis, Anabaena, Planktothrix, Aphanizomenon, Nostoc, and Phormidium [8,9]. Among them, Microcystis is considered to be the most prominent contributor to the production of MCs [10-12].

Microcystis populations are usually composed of toxigenic and non-toxigenic strains in the aquatic system [13-15]. Different Microcystis strains show varying responses to different environmental variables [16,17]. The successive replacement of toxigenic and non-toxigenic strains during the development of cyanobacterial blooms has been suggested to be the cause of the changes in MC levels [18]. However, it is not possible to distinguish between toxigenic and non-toxigenic strains of Microcystis using traditional techniques, such as morphological and pigment analyses. Recently, quantitative real-time PCR (qPCR) has been developed and widely used to estimate toxic Microcystis genotype abundance in natural populations based on specific MC synthetase genes (mcy) [19-23]. Moreover, many studies have demonstrated key factors affecting the abundance of toxic Microcystis genotypes and MC concentrations in different freshwater ecosystems. In Lake Erie, Rinta-Kanto et al. [24] have reported that the total phosphorus concentration is positively correlated with the $m c y D$ genotype and MC concentrations. The relative abundance of the $m c y A$ genotype has been shown to increase with high nitrate loading in Lake Mikata, Japan [19], whereas strong positive correlations between water temperature, $\mathrm{MC}$ concentrations, and $m c y E$ and $m c y B$ copy number have been found in the Hartbeespoort and Roodeplaat reservoirs of South Africa [25].

Lake Chaohu, which is located in Auhui Province of southeastern China $\left(31^{\circ} 40^{\prime} \mathrm{N}, 117^{\circ} 36^{\prime} \mathrm{E}\right)$, is the fifth largest freshwater lake in China (surface area: $760 \mathrm{~km}^{2}$ ). It is an important fishery and drinking water resource for more than 9.66 million people in Chaohu and Heifei city [26-28]. Due to rapid economic development and excessive exploitation of the environment, Lake Chaohu is in a eutrophic state. Since the 1980s, this lake has experienced massive cyanobacterial blooms each year during the warm seasons, with a predominance of Microcystis spp. [29,30]. Meanwhile, MC pollution in the lake is becoming more serious, and it is common for its $\mathrm{MC}$ concentrations of Lake Chaohu to exceed the 
provisional guideline of $1 \mu \mathrm{g} \mathrm{L}^{-1}$ set by the WHO [31]. Furthermore, previous observations at Lake Chaohu have shown that seasonal variation in $\mathrm{MC}$ concentrations at different sample stations and have demonstrated that the MC concentrations is correlated with water temperature and nitrogen and phosphorus levels [28,31]. Although environmental variables may affect toxicity by an order of magnitude, the overall MC concentrations in a bloom may be determined by the abundance and proportion of toxic genotypes [32,33]. However, few studies have addressed the dynamics of toxic Microcystis genotypes in Lake Chaohu and the correlations of toxic genotypes with environmental factors until now.

The purpose of this study was to investigate the relationships between MC production and the genotypic composition of the Microcystis community together with the environmental conditions in Lake Chaohu during bloom periods (from June to October in 2012). We applied qPCR to quantify specific target genes for Microcystis and toxic Microcystis to determine the genotypic composition of the natural Microcystis population. MC concentrations were considered together with qPCR data to verify the correlation between MC concentrations and the abundance of Microcystis genotypes in the lake. Moreover, the significant environmental factors that strongly influence the variations in the MC concentrations and the Microcystis population were identified through stepwise multiple regressions.

\section{Results}

\subsection{Variations in Environmental Factors}

Physical and chemical parameters from monthly water samples collected at nine sampling sites during June and October 2012 are shown in Tables 1 and S1 (Supplementary Materials). Sites 1-3 were located in the eastern part of Lake Chaohu, sites 4-6 were located in the centre of the lake, and sites 7-9 were located in the western part of the lake (Figure 1). During the study periods, the lowest water temperature $\left(18.43{ }^{\circ} \mathrm{C}\right)$ was recorded in October, while the highest $\left(30.75{ }^{\circ} \mathrm{C}\right)$ occurred in August. The chlorophyll-a (Chl-a) concentrations varied from 5.70 to $89.40 \mu \mathrm{g} \mathrm{L}^{-1}$, and the mean concentration of Chl-a in the western part of the lake was significantly higher than those in the eastern $(p<0.01)$ and central parts $(p<0.05)$. Similarly, nutrient concentrations varied typically among the nine sampling sites. The mean nutrient levels at the western sampling sites were significantly higher than those at the eastern $(p<0.01)$ and central sampling sites $(p<0.05)$. As the bloom developed, nitrate $\left(\mathrm{NO}_{3}{ }^{-}-\mathrm{N}\right)$, nitrite $\left(\mathrm{NO}_{2}{ }^{-}-\mathrm{N}\right)$ and ammonium $\left(\mathrm{NH}_{4}{ }^{+}-\mathrm{N}\right)$ decreased, while total nitrogen (TN), total phosphorus (TP) and orthophosphate $\left(\mathrm{PO}_{4}{ }^{3-}-\mathrm{P}\right)$ concentrations fluctuated. In addition, $\mathrm{pH}$ and dissolved oxygen (DO) also varied significantly among the different sampling sites during the bloom season. However, the concentrations of dissolved inorganic carbon (DIC) showed an opposite trend; the highest value was observed in the eastern part of the lake and the lowest in the western part. 
Table 1. Environmental variables summarised as the mean values and ranges in Lake Chaohu from June to October 2012.

\begin{tabular}{cccc}
\hline Parameter & Eastern Lake & Central Lake & Western Lake \\
\hline $\mathrm{TN}\left(\mathrm{mg} \mathrm{L}^{-1}\right)$ & $0.92(0.56-1.48)$ & $1.44(0.70-0.25)$ & $2.84(1.45-5.09)$ \\
$\mathrm{NH}_{4}{ }^{+}-\mathrm{N}\left(\mathrm{mg} \mathrm{L}^{-1}\right)$ & $0.15(0.04-0.42)$ & $0.17(0.04-0.30)$ & $0.56(0.09-3.55)$ \\
$\mathrm{NO}_{3}{ }^{-}-\mathrm{N}\left(\mathrm{mg} \mathrm{L}^{-1}\right)$ & $0.12(0.07-0.25)$ & $0.13(0.06-0.29)$ & $0.36(0.08-0.70)$ \\
$\mathrm{NO}_{2}{ }^{-}-\mathrm{N}\left(\mathrm{mg} \mathrm{L}^{-1}\right)$ & $0.01(0.00-0.02)$ & $0.01(0.00-0.06)$ & $0.08(0.00-0.37)$ \\
$\mathrm{TP}\left(\mathrm{m} \mathrm{L} \mathrm{L}^{-1}\right)$ & $0.05(0.03-0.09)$ & $0.11(0.03-0.23)$ & $0.20(0.07-0.39)$ \\
$\mathrm{PO}_{4}^{3-}-\mathrm{P}\left(\mathrm{mg} \mathrm{L}^{-1}\right)$ & $0.00(0.00-0.01)$ & $0.02(0.00-0.05)$ & $0.06(0.01-0.26)$ \\
$\mathrm{DIC}\left(\mathrm{mg} \mathrm{L}^{-1}\right)$ & $14.55(13.40-16.22)$ & $13.92(10.59-17.71)$ & $12.60(8.74-15.06)$ \\
$\mathrm{DOC}\left(\mathrm{mg} \mathrm{L}^{-1}\right)$ & $4.64(3.40-5.67)$ & $4.78(4.01-5.52)$ & $5.40(4.26-7.46)$ \\
$\mathrm{Chl}-\mathrm{a}\left(\mu \mathrm{g} \mathrm{L}^{-1}\right)$ & $14.42(5.70-62.28)$ & $30.19(7.80-65.43)$ & $37.56(10.72-89.40)$ \\
Water temperature $\left({ }^{\circ} \mathrm{C}\right)$ & $25.74(19.18-30.75)$ & $25.30(18.44-30.41)$ & $24.98(18.43-30.04)$ \\
$\mathrm{pH}$ & $7.41(4.73-9.12)$ & $7.76(5.51-9.36)$ & $7.83(6.12-9.40)$ \\
DO $\left(\mathrm{mg} \mathrm{L}^{-1}\right)$ & $9.37(4.47-14.14)$ & $8.64(4.79-10.35)$ & $8.34(4.59-14.97)$ \\
Secchi depth $(\mathrm{m})$ & $52.33(28.00-85.00)$ & $35.73(17.00-90.00)$ & $28.54(15.00-45.00)$ \\
Water depth $(\mathrm{m})$ & $3.70(2.30-4.50)$ & $3.81(1.90-4.50)$ & $3.21(1.90-4.00)$ \\
Conductivity $\left(\mu \mathrm{S} \mathrm{cm}{ }^{-1}\right)$ & $315.07(280.00-370.00)$ & $289.07(213.00-361.00)$ & $315.10(223.00-392.00)$ \\
\hline
\end{tabular}

Figure 1. Map of Lake Chaohu with sampling sites.

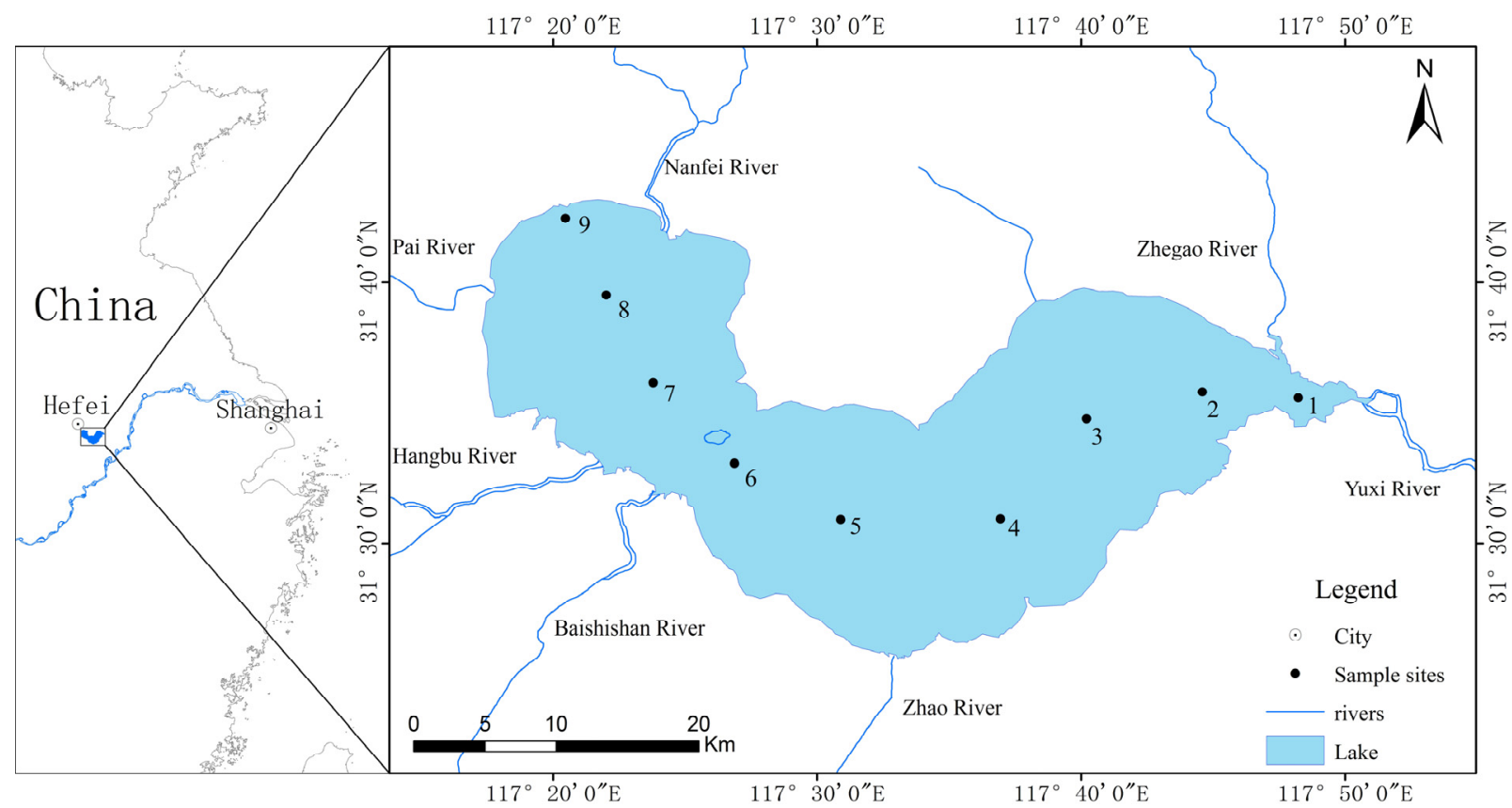

\subsection{Dynamics of Microcystis Genotypes and MC Concentrations in Water Samples}

The real-time PCR data showed log-linear relationships for both the $16 \mathrm{~S}$ rDNA and $m c y D$ gene copy number when the genomic DNA from M. aeruginosa PCC7806 was used as a template, and the PCR efficiencies of the $16 \mathrm{~S}$ rDNA and $m c y D$ standard curves were 0.99 and 0.96 , respectively. The melting curves of the $16 \mathrm{~S}$ rDNA and $m c y D$ real-time PCR products showed peaks at approximately 89.2 and $84.5{ }^{\circ} \mathrm{C}$, respectively, corresponding to the melting temperature of the standard strain M. aeruginosa PCC 7806, thereby demonstrating the reliability of the real-time PCR amplification. 
Both the total Microcystis and potentially toxic Microcystis genotypes were detected by real-time PCR in all of the water samples. During the study period, the abundances of total and toxic Microcystis

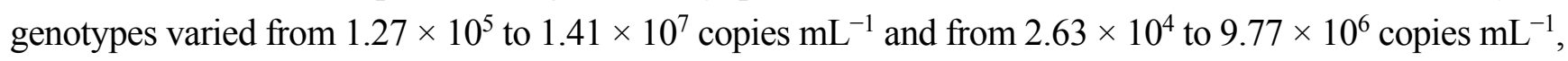
respectively (Figure 2). The gene copy numbers for the total and toxic Microcystis genotypes at the western sampling sites 7-9 were significantly higher than those at the eastern sampling sites 1-3 $(p<0.01)$ (Figures 3 and 4). The highest copy numbers for the total and toxic Microcystis genotypes $\left(1.41 \times 10^{7}\right.$ and $9.77 \times 10^{6}$ copies $\left.\mathrm{mL}^{-1}\right)$ occurred at site 9 in August, whereas the corresponding lowest values $\left(1.27 \times 10^{5}\right.$ and $2.63 \times 10^{4}$ copies $\left.\mathrm{mL}^{-1}\right)$ were recorded at sites 1 and 2 , respectively, in October. Meanwhile, the proportion of potentially toxic Microcystis genotypes within the total Microcystis population ranged from $9.43 \%$ to $87.98 \%$ and showed a trend that was very similar to the abundances of total and toxic Microcystis genotypes. The highest proportion was recorded at western sampling site 8 in July, while the lowest value was recorded at eastern sampling site 3 in September (Figure 5).

During the bloom period, the total MC concentrations varied across locations and sampling times, ranging from 1.06 to $17.61 \mu \mathrm{g} \mathrm{L}^{-1}$, with the highest level occurring at site 9 in August and the lowest detected at site 1 in June (Figures 2 and 6). The MC concentrations in water from Lake Chaohu were above the provisional guideline for drinking water of $1.0 \mu \mathrm{g} \mathrm{L}^{-1}$ recommended by the World Health Organization [34].

Figure 2. The abundance of total Microcystis and toxic Microcystis genotypes and MC concentrations at all the water sampling sites in the Lake Chaohu.

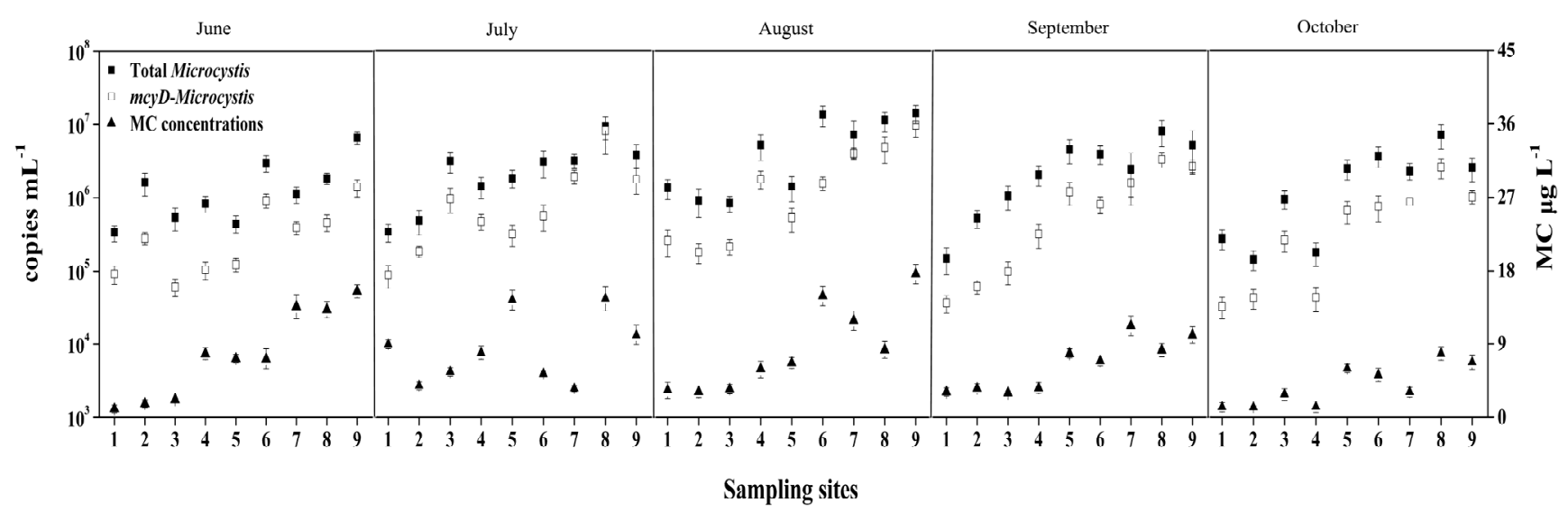


Figure 3. The spatial distribution of total Microcystis abundance in Lake Chaohu from June to October 2012. The unit of measurement was $10^{6}$ copies $\mathrm{mL}^{-1}$. The interpolation map was constructed by ArcGIS software using the Inverse Distance Weighting method.

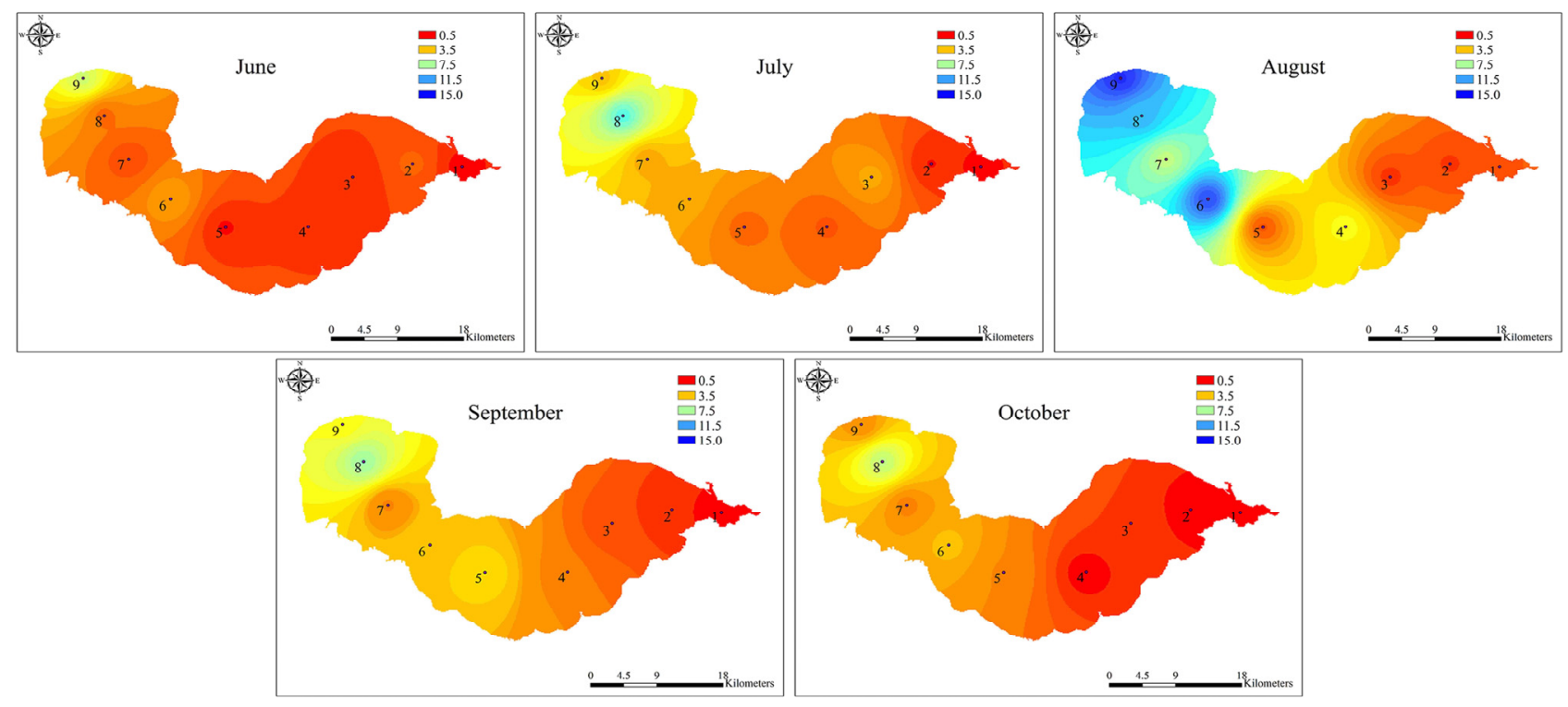

Figure 4. The spatial distribution of toxic Microcystis abundance in Lake Chaohu from June to October 2012. The unit of measurement was $10^{6}$ copies $\mathrm{mL}^{-1}$. The interpolation map was constructed by ArcGIS software using the Inverse Distance Weighting method.

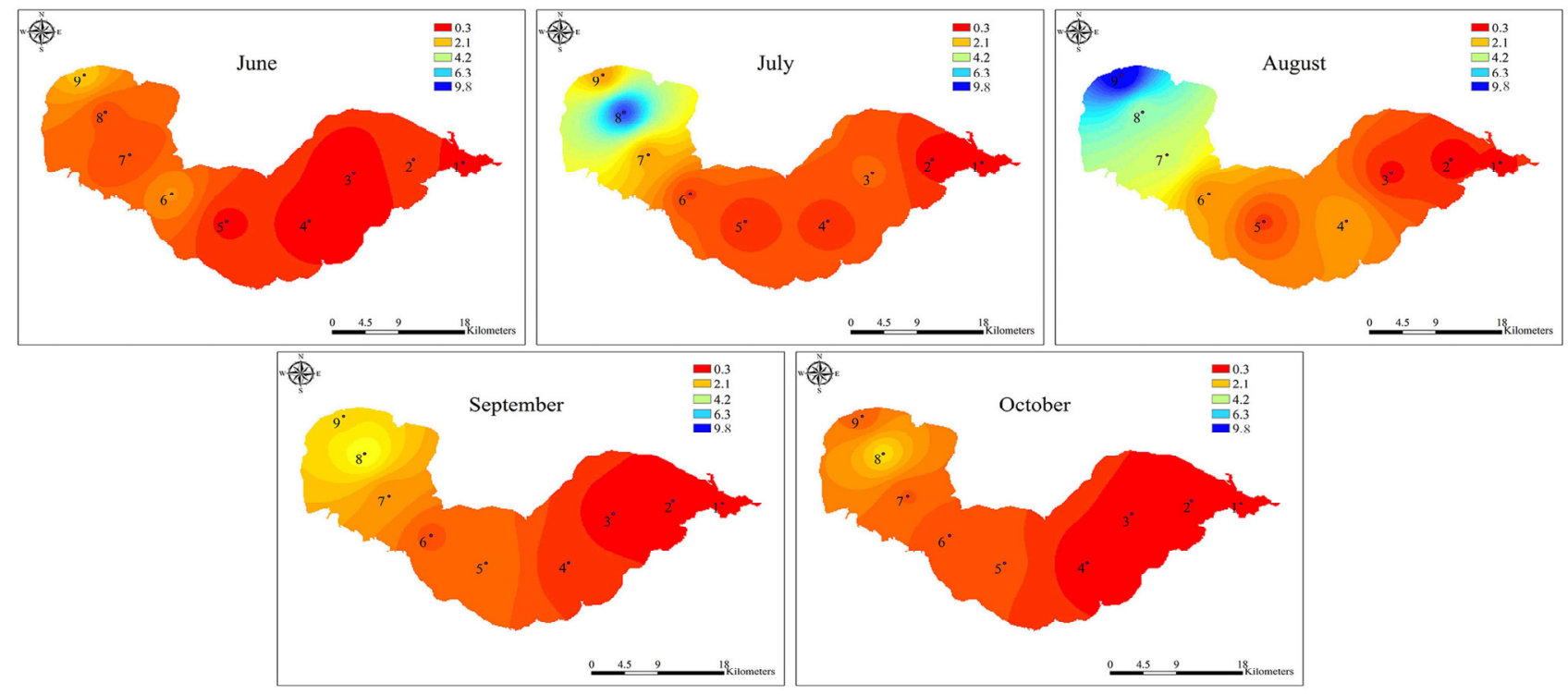


Figure 5. The proportion of toxic Microcystis among the total Microcystis population in Lake Chaohu from June to October 2012.

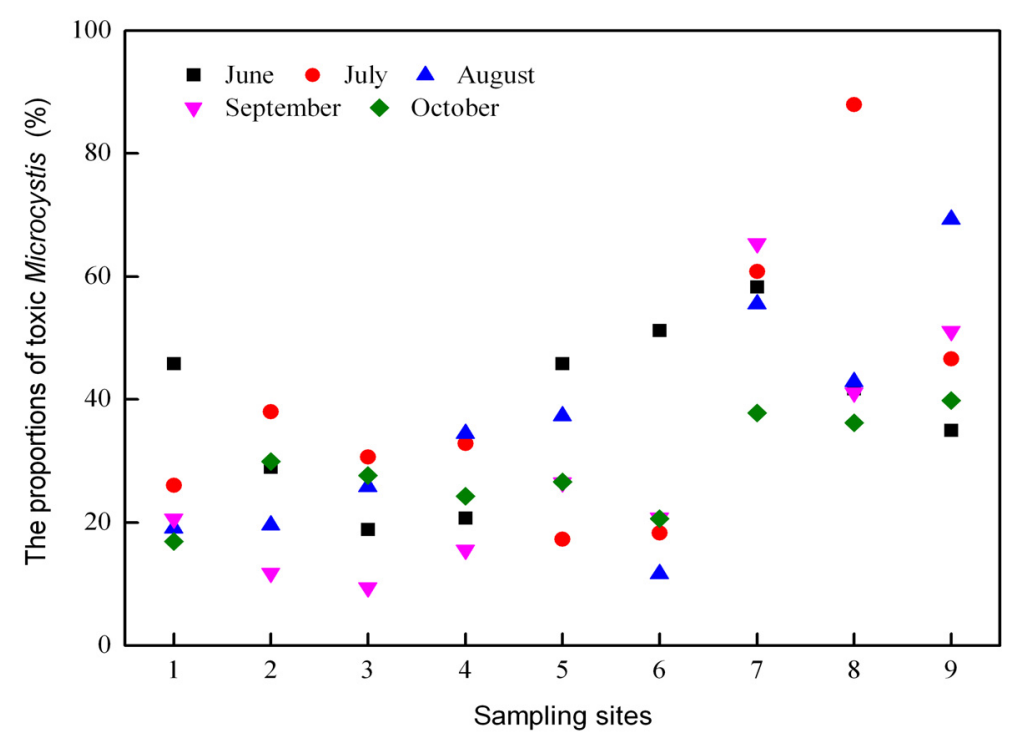

Figure 6. The spatial distribution of total MC concentrations in Lake Chaohu from June to October 2012. The interpolation map was constructed by ArcGIS software using the Inverse Distance Weighting method.

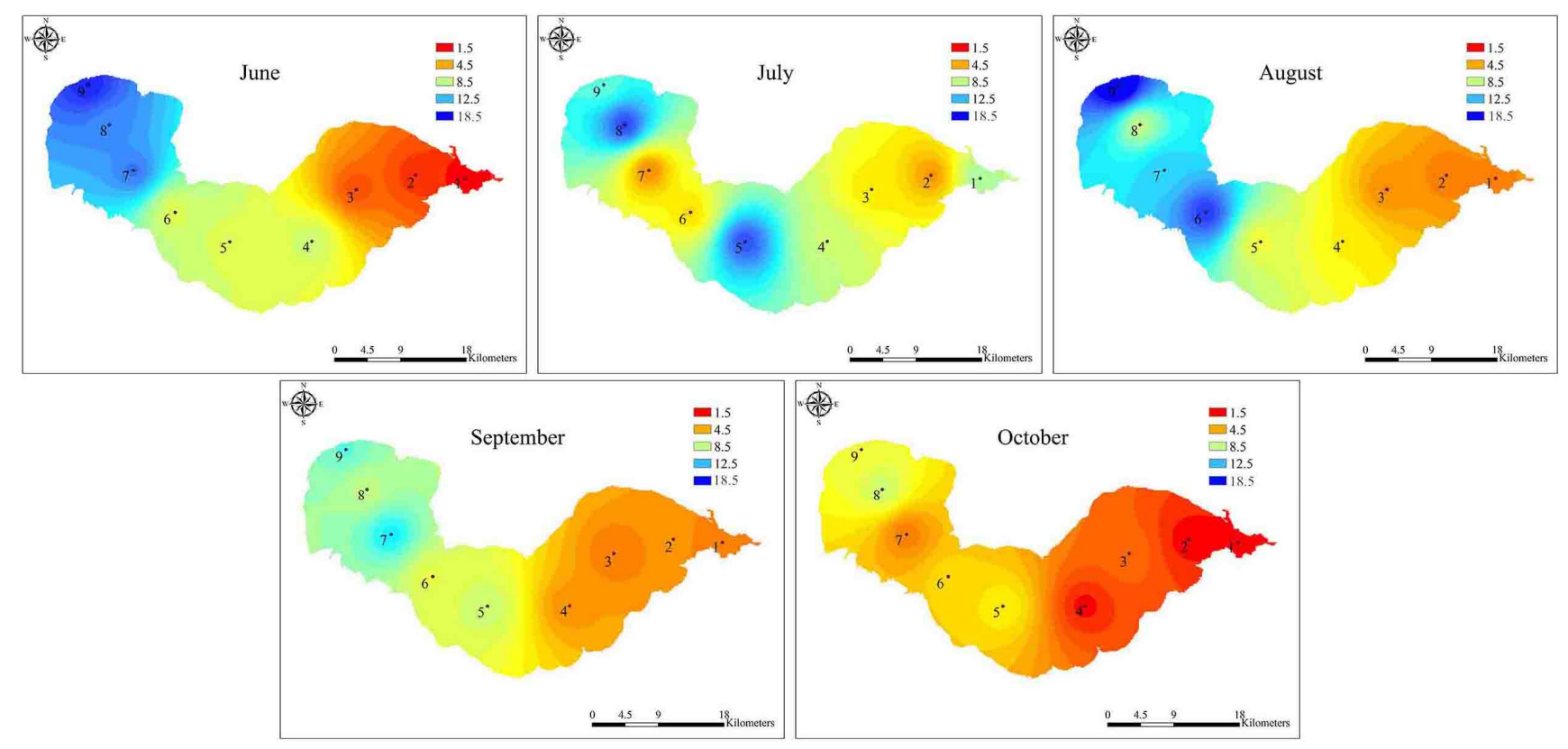

2.3. Relationships of Environmental Variables with MC Concentrations, Microcystis 16S rDNA and mcyD Genotypes Abundance

The Pearson correlation coefficients $(r)$ and probability values $(p)$ for each correlation are shown in Table 2. The total Microcystis 16S rDNA and mcyD genotypes were strongly correlated with each other $(r=0.941, p<0.001, n=45)$. The total MC concentrations showed a strong positive correlation with the abundance of Microcystis $16 \mathrm{~S}$ rDNA and $m c y D$ copies, and the proportion of toxic genotypes in the Microcystis population. 
The data showed that the total MC concentrations and the abundance of Microcystis 16S rDNA and the $m c y D$ copies were positively correlated with $\mathrm{TP}, \mathrm{TN}, \mathrm{NH}_{4}{ }^{+}-\mathrm{N}, \mathrm{NO}_{3}{ }^{-}-\mathrm{N}, \mathrm{PO}_{4}{ }^{3-}-\mathrm{P}$, water temperature, and $\mathrm{pH}(p<0.05)$. Nevertheless, DIC showed a negative relationship with each of the three parameters $(p<0.05)$. In addition, the associations of the Chl- $a$ concentration with MC concentrations and the copy numbers of each target gene were positive $(p<0.05)$, but the mcyD copy numbers and $\mathrm{MC}$ concentrations were negatively correlated with Secchi depth and water depth $(p<0.05)$, and were not correlated with DO or conductivity $(p>0.05)$.

Table 2. Pearson correlation coefficients ( $r$ ) for correlations between environmental factors, Microcystis genotypes and microcystins concentration (MC) concentrations $(n=45)$. Significant values $(p<0.05)$ are in bold type.

\begin{tabular}{|c|c|c|c|c|c|c|}
\hline \multirow{2}{*}{ Variable } & \multicolumn{2}{|c|}{ Microcystis 16S rDNA } & \multicolumn{2}{|c|}{ Toxic Microcystis mcyD } & \multicolumn{2}{|c|}{ MC } \\
\hline & $r$ & $p$ & $r$ & $p$ & $r$ & $p$ \\
\hline Toxic Microcystis mcyD & 0.941 & 0.000 & - & - & - & - \\
\hline $\mathrm{MC}$ & 0.670 & 0.000 & 0.690 & 0.000 & - & - \\
\hline$\%$ toxic proportion & 0.310 & $\mathbf{0 . 0 3 9}$ & 0.595 & 0.000 & 0.394 & 0.007 \\
\hline $\mathrm{TN}$ & 0.532 & 0.000 & 0.598 & 0.000 & 0.625 & 0.000 \\
\hline $\mathrm{NH}_{4}^{+}-\mathrm{N}$ & 0.298 & 0.046 & 0.351 & 0.018 & 0.368 & 0.013 \\
\hline $\mathrm{NO}_{3}{ }^{-}-\mathrm{N}$ & 0.325 & 0.029 & 0.457 & 0.002 & 0.289 & 0.054 \\
\hline $\mathrm{NO}_{2}{ }^{-}-\mathrm{N}$ & 0.273 & 0.069 & 0.364 & 0.014 & 0.381 & 0.010 \\
\hline $\mathrm{TP}$ & 0.599 & 0.000 & 0.608 & 0.000 & 0.675 & 0.000 \\
\hline $\mathrm{PO}_{4}{ }^{3-}-\mathrm{P}$ & 0.381 & 0.010 & 0.396 & 0.007 & 0.379 & 0.010 \\
\hline DIC & -0.467 & 0.001 & -0.359 & 0.015 & -0.374 & 0.011 \\
\hline DOC & 0.395 & 0.007 & 0.432 & 0.003 & 0.554 & 0.000 \\
\hline Chl-a & 0.562 & 0.000 & 0.553 & 0.000 & 0.656 & 0.000 \\
\hline Temperature & 0.302 & 0.038 & 0.334 & 0.026 & 0.324 & 0.022 \\
\hline $\mathrm{pH}$ & 0.263 & 0.008 & 0.314 & 0.036 & 0.423 & 0.004 \\
\hline DO & -0.051 & 0.741 & -0.038 & 0.803 & 0.024 & 0.875 \\
\hline Secchi depth & -0.365 & 0.014 & -0.356 & 0.016 & -0.398 & 0.007 \\
\hline Water depth & -0.156 & 0.308 & -0.264 & 0.008 & -0.384 & 0.009 \\
\hline Conductivity & -0.126 & 0.409 & -0.002 & 0.987 & -0.006 & 0.970 \\
\hline
\end{tabular}

2.4. Stepwise Multiple Regressions Determining Significant Environmental Variables Correlated with MC Concentrations and Abundance of Microcystis $16 S$ rDNA and mcyD Genotypes (Stepwise Multiple Regression Analyses Were Performed to Determine the Key Environmental Variables that Explained the Abundances of MC and Total and Toxic Microcystis in Lake Chaohu (Table 3))

The first model for predicting total Microcystis abundance from environmental variables accounted for over $50 \%\left(R^{2}\right.$-adj $\left.=0.53\right)$ of the variance and included TP, DIC and water temperature. This model revealed that TP contributed the greatest to the explanation of the variation in the abundance of Microcystis 16S rDNA copies $\left(R^{2}=0.36\right)$, followed by DIC and water temperature. Microcystis 16S rDNA copy abundance was positively correlated with TP and water temperature but negatively correlated with DIC. Thus, the occurrence probability of the Microcystis 16S rDNA copies increases with increasing TP and water temperature and decreasing DIC. 
A second model relating the abundance of toxic Microcystis mcyD copies to environmental variables accounted for over $58 \%\left(R^{2}\right.$-adj $\left.=0.59\right)$ of the variance, with TP, water temperature, DIC and $\mathrm{NO}_{3}{ }^{-}-\mathrm{N}$ representing the significant contributors $(p<0.05$; Table 3$)$. TP also was the most explanatory factor, and each variable had a positive relationship with toxic Microcystis, except for DIC.

A third model describing the MC concentrations accounted for over $70 \%$ of the variation $\left(R^{2}\right.$-adj $\left.=0.72\right)$. This final model included the following variables: TP, water temperature, and DIC. TP and water temperature were the significant components. Although DIC explained less than TP and water temperature, it was an important explanatory variable for MC concentrations variation. DIC was inversely related to MC concentrations, such that the MC concentrations increased as DIC decreased.

Table 3. Three multiple linear regression models for predicting total and toxic Microcystis abundance and total MC concentrations in Lake Chaohu. The corresponding $p$-values and coefficients are given for each variable in the model. $R^{2}$-adjusted (adj) values given are a measure of the total variance described by the model when only the components listed are used. $R^{2}$-adjusted is a modified statistical term which incorporates a correction for the positive bias of $R^{2}$.

\begin{tabular}{|c|c|c|c|}
\hline Model and Variable & $R^{2}$ & Coefficient & $p$-Value \\
\hline \multicolumn{4}{|c|}{ Total Microcystis 16S rDNA $\left(R^{2}\right.$-adj $\left.=0.53, p<0.001\right)$} \\
\hline Constant & - & 5.872 & 0.001 \\
\hline TP & 0.359 & 11.441 & 0.000 \\
\hline DIC & 0.480 & -2.724 & 0.006 \\
\hline Temp & 0.555 & 1.979 & 0.012 \\
\hline \multicolumn{4}{|c|}{ Toxic Microcystis mcyD $\left(R^{2}\right.$-adj $\left.=0.59, p<0.001\right)$} \\
\hline Constant & - & 5.033 & 0.014 \\
\hline TP & 0.370 & 10.765 & 0.000 \\
\hline Temp & 0.516 & 2.667 & 0.003 \\
\hline DIC & 0.561 & -3.490 & 0.004 \\
\hline $\mathrm{NO}_{3}{ }^{-}-\mathrm{N}$ & 0.625 & 3.558 & 0.013 \\
\hline \multicolumn{4}{|c|}{$\mathrm{MC}\left(R^{2}\right.$-adj $\left.=0.72, p<0.001\right)$} \\
\hline Constant & - & -0.162 & 0.835 \\
\hline $\mathrm{TP}$ & 0.391 & 7.605 & 0.000 \\
\hline Temp & 0.625 & 1.892 & 0.000 \\
\hline DIC & 0.735 & -1.816 & 0.000 \\
\hline
\end{tabular}

\section{Discussion}

This investigation in Lake Chaohu explored the correlations among Microcystis population dynamics, MC concentrations and environmental variables. Our results suggested that toxic Microcystis genotypes coexisted with the non-toxic Microcystis genotypes, and that the abundance of Microcystis genotypes and MC production varied across spatial and temporal scales. These results were supported by the Pearson correlation and stepwise multiple regressions analyses that showed total phosphorus, water temperature and dissolved inorganic carbon were the primary variables regulating the variations in Microcystis population dynamics and MC concentrations during the bloom season.

Lake Chaohu is located in the subtropical climate zone, which the total sun radiation is about $499 \mathrm{~kJ} /\left(\mathrm{cm}^{2} \mathrm{a}\right)$, the annual mean temperature is about $16{ }^{\circ} \mathrm{C}$, and the annual rainfall is $1100 \mathrm{~mm}$. 
These conditions combined with the shallow water depth and high nutrient concentrations, provide the favorable conditions for cyanobacteria mass proliferation [35]. Consequently, this lake exhibits annual heavy cyanobacteria blooms, leading to higher MC concentrations. The results from the present study showed that MC concentrations were positively correlated with the abundance of Microcystis mcyD copies $(r=0.69, p<0.001, n=45)$. However, interestingly, the abundance of toxic Microcystis in June was relatively low at sites 7-9 in the western part of the lake (Figure 4), while MC concentrations were remarkably high and comparable with that in August, when the highest abundance of toxic Microcystis was observed (Figures 2, 4 and 6). This inconsistency may be due to the production of MCs by other species in June. In fact, the potential MC-producing cyanobacterial genera Aphanizomenon and Anabaena were observed in Lake Chaohu, especially in June when the bloom was found to be composed mainly of Aphanizomenon, Anabaena and Microcystis. Among these species, the average biomass of Aphanizomenon represented $50.6 \%$ of the total cyanobacteria, Anabaena comprised 28.5\% and Microcystis accounted for 19.9\% [36]. Therefore, a proportion of the MCs detected in June may have been released from Aphanizomenon and Anabaena. Although there are other potential MC-producing cyanobacteria present in Lake Chaohu, one cannot deny that Microcystis as the major contributor to $\mathrm{MC}$ production during the summer, when it was predominant in the lake.

Data from qPCR showed that in Lake Chaohu, toxic Microcystis genotypes coexisted with non-toxic Microcystis genotypes. The proportion of toxic and non-toxic Microcystis, which reflected the abundance of Microcystis $16 \mathrm{~S}$ rDNA and mcyD copies, varied across sites and phases of the bloom development (Figures 2-4). Proportions of toxic Microcystis genotypes varied from $9.43 \%$ to $87.98 \%$, which is in agreement with previous investigations of several lakes where toxic genotypes are generally lower than the abundance of total Microcystis in natural algal populations [19,24,37,38]. Some of these investigations have revealed that the proportions of mcy-containing Microcystis are relatively low, such as 1\%-38\% for $m c y B$ subpopulations in Lake Wannsee, Germany [37], 0.5\%-35\% for $m c y A$ subpopulations in Lake Mikata, Japan [19], and $0 \%-37 \%$ for $m c y D$ subpopulations in Lake Oneida, USA [38], while higher proportions of toxigenic Microcystis have been observed in Lake Volkerak, the Netherlands [13] and Lake Ronkonkoma, USA [17]. In the present study, the eastern and western regions of the lake showed low and high toxic proportions of Microcystis, respectively (Figure 5). This spatial difference may be explained by the fact that the eutrophication levels for the western region were significantly higher than that for eastern region. High nutrient concentrations are able to maintain high abundance of Microcystis, with a much higher proportion of toxigenic genotypes.

The MC concentrations showed a similar pattern as the Microcystis 16S rDNA and mcyD copies, with their highest abundance all recorded at the western site 9 in August. In accordance with the proportion of toxic Microcystis genotypes, the MC concentrations at the western sampling sites of Lake Chaohu were significantly higher than those at the eastern sampling sites (Figure 6). This finding and similar results from other studies [25] suggest that these changes in the MC concentrations can be attributed to variations in genotype composition within the cyanobacterial community [38]. During the study period, the MC concentrations increased as the blooms developed, and the peak value reached $17.61 \mu \mathrm{g} \mathrm{L}^{-1}$, which is similar to a previous reported by Yang et al. [31]. Yang and colleagues have conducted an extensive investigation of Lake Chaohu, and have found $\mathrm{MC}$ pollution throughout the entire lake, particularly in the western region. MCs are chemically very stable and do not readily undergo proteolytic or hydrolytic attack [39], long-term exposure to MCs in the field is expected to 
adversely affect the detoxification capabilities of aquatic organisms [40]. In Lake Chaohu, the tissue distribution and bioaccumulation of MCs have been reported in fish, shrimp, and mussels at different trophic levels [41-43], whereas fishermen frequenting this lake have hepatocellular damage and alarming serum concentrations due to chronic MC exposure [44]. Together with the current study, these data suggest that Lake Chaohu may be unsafe for fish and drinking water use and further monitoring is recommended.

Microcystis dynamics and MC production have been demonstrated to be associated with environmental factors in previous studies [17,45-48]. In our study, the abundance of Microcystis $16 \mathrm{~S}$ rDNA and $m c y D$ copies and MC concentrations showed significant positive correlations with TP, TN, $\mathrm{NH}_{4}{ }^{+}-\mathrm{N}, \mathrm{NO}_{3}{ }^{-}-\mathrm{N}, \mathrm{PO}_{4}{ }^{3-}-\mathrm{P}$, water temperature, and $\mathrm{pH}$. Negative correlations were observed with Secchi depth, water depth, and DIC.

According to the regression models, Microcystis 16S rDNA and mcyD copy abundances and the MC concentrations showed strong positive correlations with TP, indicating that increasing the phosphorus (P) concentration could increase the toxic Microcystis abundance and MC production. Our observation agreed with those from a study conducted in the large eutrophic Lake Erie in USA [24], where positive correlations between TP and the abundance of toxic Microcystis and MC were found. Vézie et al. [49] have also found that higher P concentrations are beneficial to the growth of toxic Microcystis and MC synthesis. Consistent with the trend, Davis et al. [17] have reported that the growth rate of toxic Microcystis exceeds the non-toxic strains under elevated P concentrations. These results could be explained by the fact that toxic Microcystis has significant $\mathrm{P}$ requirements associated with the enzymes involved in the synthesis of $\mathrm{MC}$, as well as with additional light-harvesting pigments that they may possess [50,51]. Although TP was a dominant explanatory variable, the effect of nitrogen $(\mathrm{N})$ on the Microcystis dynamics and MC production cannot be ignored. $\mathrm{MC}$ is an $\mathrm{N}$-rich compound; thus, toxic Microcystis has additional $\mathrm{N}$ requirements associated with MC synthesis [50]. Previous studies have also demonstrated that increasing the $\mathrm{N}$ concentration could promote the growth and toxicity of Microcystis [52-54]. Furthermore, both correlation and stepwise multiple regression analyses in our study showed that toxic Microcystis abundance and $\mathrm{MC}$ concentrations were positively correlated with $\mathrm{TN}$ and $\mathrm{NO}_{3}{ }^{-}-\mathrm{N}$, consistent with many other studies [28,31,55].

In Lake Chaohu, the higher TP and TN concentrations in the western part of the lake may have promoted favorable conditions for Microcystis and MC synthesis, thus leading to the increased abundance of toxic Mirocystis and MC production in western Lake Chaohu compared to the eastern region. Similar phenomenon was observed in Lake Taihu [56], where spatial differences in the abundance of toxic Microcystis and the MC concentrations were positively correlated with TP and TN. All of these results suggest that increasing nutrient concentrations, especially TP, may promote the growth of a toxic, rather than non-toxic, population of Microcystis, resulting in blooms with higher MC concentrations.

Temperature is the primary driving factor of the proliferation of cyanobacteria in natural freshwater [57]. Harmful cyanobacteria such as Microcystis, have an optimal temperature for growth at, or above, $25{ }^{\circ} \mathrm{C}[16,58,59]$. Rising temperatures not only promote the dominance of Microcystis but may favour the proliferation of toxic Microcystis strains and result in an increase in the MC concentrations [60]. According to the models, temperature was associated with the 16S rDNA and 
$m c y D$ copy abundances and $\mathrm{MC}$ concentrations, particularly in August, when the copy numbers of the $16 \mathrm{~S}$ rDNA and $m c y D$ genes at the maximum along with a peak in the total MC concentrations. This finding may support the previous hypothesis that factors increasing the growth rate of cells also enhance MC production [17,49,53,61]. Positive relationships between temperature, Microcystis abundance and MC production have been observed in other cyanobacterial-prone bodies of water, including Lake Taihu, in China [62] and two reservoirs, namely Hartbeespoort and Roodeplaat, in South African [25]. These results and our data support the prediction from Paerl and Huisman [16] that future global warming can lead to toxic Microcystis blooms of longer durations.

By contrast, the model describing the abundances of $16 \mathrm{~S}$ rDNA and $m c y D$ copies and the MC concentration showed negative correlations with DIC, suggesting that the decrease in DIC concentration was accompanied by increases in the $16 \mathrm{~S}$ rDNA and mcyD copy mumbers and the MC concentrations in Lake Chaohu. Because cyanobacteria are better competitors for DIC [63,64], several taxa, including Microcystis are able to use bicarbonate as a carbon source when $\mathrm{CO}_{2}$ availability is limited [65,66]. In our study, $\mathrm{pH}$ was often above 8, even reaching 9 during the summer (Table 1), indicating that $\mathrm{CO}_{2}$ availability was quite low [67]. However, the copy numbers of $16 \mathrm{~S}$ rDNA and $m c y D$ and $M C$ concentrations reached their peaks, supporting the hypothesis that low $\mathrm{CO}_{2}$ conditions, particularly in a eutrophic lake, may favour Microcystis growth $[63,68,69]$. Moreover, variations in the MC concentrations may be moderated by $\mathrm{CO}_{2}$ availability [70-72]. Additionally, Van de Waal et al. [73] have demonstrated that toxic Microcystis has a competitive advantage and grows better at low $\mathrm{CO}_{2}$ concentrations, thereby increasing the MC concentrations. Conversely, toxic Microcystis has lost this advantage and is associated with low $\mathrm{MC}$ concentrations under elevated $\mathrm{CO}_{2}$ concentrations. These results suggest that rising $\mathrm{CO}_{2}$ concentrations may decrease toxic Microcystis abundance and $\mathrm{MC}$ concentrations in the future.

\section{Experimental Section}

\subsection{Sampling Sites and Collection Methods}

Nine fixed sampling sites in Lake Chaohu were selected for water sampling (Figure 1). Sites 1-3 were located in the eastern part of Lake Chaohu, sites 4-6 were located in the centre of the lake, and sites 7-9 were located in the western part. Triplicate water samples were collected monthly from the surface layer $(0.5 \mathrm{~m})$ with a sterile sampler from June to October 2012. All samples were preserved in sterile bottles and transported to the laboratory on ice. The water samples were filtered using GF/C filters (pore size, $1.2 \mu \mathrm{m}$; Whatman, Maidstone, England, UK), and the filters containing the phytoplankton samples were immediately kept frozen at $-80^{\circ} \mathrm{C}$ until DNA extraction and $\mathrm{MC}$ analysis.

\subsection{Environmental Variables}

Water temperature, DO, conductivity and $\mathrm{pH}$ were measured in situ with a multiparameter water quality sonde (YSI 6600, Yellow Spring Instruments, Yellow Springs, OH, USA). Water depth was measured using a Portable Depth Sounder (SM-5, SpeedTech Instruments, Great Falls, VA, USA). Water transparency was measured with a Secchi disk. TP was analysed according to the ammonium molybdate spectrophotometric method (GB11893-89, China), and TN was determined by the alkaline 
potassium persulphate digestion-UV spectrophotometric method (GB11894-89, China). To determine the levels of dissolved inorganic nutrients, including $\mathrm{PO}_{4}{ }^{3-}-\mathrm{P}, \mathrm{NO}_{3}{ }^{-}-\mathrm{N}, \mathrm{NO}_{2}{ }^{-}-\mathrm{N}$ and $\mathrm{NH}_{4}{ }^{+}-\mathrm{N}, 50 \mathrm{~mL}$ of the water sample was filtered through a GF/F glass fiber filter (pore size, $0.8 \mu \mathrm{m}$; Whatman, Maidstone, England, UK) and analysed using a continuous flow analyser (San plus system, Skalar, Breda, The Netherlands) according to the manufacturer's instructions. DIC and dissolved organic carbon (DOC) were analysed on filtrates from samples filtered through $\mathrm{GF} / \mathrm{F}$ glass fiber filter (pore size, $0.8 \mu \mathrm{m}$; Whatman, Maidstone, England, UK; via burning in the muffle furnace for $4 \mathrm{~h}$ at $500{ }^{\circ} \mathrm{C}$ ), and measured by high temperature burning method with a TOC analyzer (Torch, Teledyne Tekmar, Mason, OH, USA). To analyse Chl-a concentrations, the triplicate water samples were filtered through $\mathrm{GF} / \mathrm{C}$ filters (pore size, $1.2 \mu \mathrm{m}$; Whatman, Maidstone, England, UK) and measured according to Lorenzen [74] with spectrophotometric measurements after extraction in hot $90 \%$ ethanol.

\subsection{Microcystin (MC) Analysis}

Lake water $(500 \mathrm{~mL})$ was filtered through a GF/C glass fiber filter (pore size, $1.2 \mu \mathrm{m}$; Whatman, Maidstone, England, UK) in triplicate to separate the microcystin dissolved in water (extracellular MC) and microcystin in particles (intracellular MC). For intracellular MC analysis, the filters were lyophilised and extracted with 5\% ( $v / v)$ acetic acid solution followed by $80 \%(v / v)$ aqueous methanol [75], with an additional step involving the grinding of the filters using a Fast Prep-24 automated homogeniser (MP Biomedicals, Santa Ana, CA, USA) with 0.5-mm silica beads. After centrifugation (9500 r/min, $10 \mathrm{~min}$ ), the supernatants were pooled and diluted with distilled water, and the distilled supernatants were concentrated using solid-phase extraction cartridges $(\mathrm{C} 18,0.5 \mathrm{~g})$ and eluted with $100 \%(0.1 \%$ TFA $)$ methanol. After being blown dry with nitrogen at $40{ }^{\circ} \mathrm{C}$, the residues were each re-suspended in $150 \mu \mathrm{L}$ of $50 \%$ aqueous methanol prior to HPLC analysis. Extracellular microcystin concentrations were determined by the filtration of $500 \mathrm{~mL}$ of lake water using GF/C filters (pore size, $1.2 \mu \mathrm{m}$; Whatman, Maidstone, England, UK) and were concentrated with solid phase extraction cartridges. The next steps involving nitrogen blow-drying and methanol resuspension were performed as described for the intracellular MC extraction.

MC was analysed using high-performance liquid chromatography with photodiode array detection (Agilent 1200, Agilent, Palo Alto, CA, USA) equipped with an ODS column (Agilent Eclipse XDB-C18, $5 \mu \mathrm{m}, 4.6 \mathrm{~mm} \times 150 \mathrm{~mm}$ ), using a gradient of 30 to $70 \%(v / v)$ acetonitrile (with $0.05 \%(v / v)$ trifluoroacetic acid) at a flow rate of $1 \mathrm{~mL} \mathrm{~min}^{-1}$. MC was identified by its characteristic UV spectra. Total MC concentrations were quantified as the sum of all MC peaks using MC-LR, -RR, and -YR standards (Sigma, München, Germany).

\subsection{DNA Extraction and Quantitative Real-Time PCR}

The GF/C filters were cut into small pieces with a sterile scalpel. Total DNA was extracted using the potassium xanthogenate sodium dodecyl sulfate method as described previously [76].

Real-time PCR assay was used to quantify the 16S rDNA and $m c y D$ gene regions. The 16S rDNA gene primers 184F (5'-GCCGCRAGGTGAAAMCTAA-3') and 431R (5'-AATCCAAARACCTTCCTCCC-3') were used to quantify the abundance of the total Microcystis population [77], whereas the mcyD gene 
primers F2 (5'-GGTTCGCCTGGTCAAAGTAA-3') and R2 (5'-CCTCGCTAAAGAAGGGTTGA-3') were used to detect the abundance of the toxic Microcystis population [78].

To construct a standard curve for real-time PCR analysis, MC-producing Microcystis aeruginosa PCC 7806, which was obtained from the FACHB-Collection (Freshwater Algal Culture Collection of the Institute of Hydrobiology, China), was used as a standard strain. The standard curves showing the relationships between the target gene copy numbers and the threshold cycles $\left(C_{t}\right)$ were generated with serial dilutions of genomic DNA. M. aeruginosa 7806 was grown in BG-11 medium at $25{ }^{\circ} \mathrm{C}$ and $60 \mu \mathrm{mol}$ photons $\mathrm{m}^{-2} \cdot \mathrm{s}^{-1}$. Cells from a known volume of the $M$. aeruginosa PCC 7806 culture were filtered through GF/C filters, and the DNA extraction was conducted as described above. The DNA concentration (ABS260) and purity (ABS260/ABS280) were determined spectrophotometrically. A 10 -fold dilution series of the DNA was prepared, and the $16 \mathrm{~S}$ rDNA and $m c y D$ genes were amplified by real-time PCR. The copy numbers of these two genes above were calculated according to Vaitomaa et al. [21].

Real-time PCR was performed with a Mastercycler realplex 4 system (Eppendorf, Hamburg, Germany) using $25 \mu \mathrm{L}$ of a reaction mixture, which containing $12.5 \mu \mathrm{L}$ of SYBR Premix EX Taq ${ }^{\mathrm{TM}}$ (TaKaRa, Kusatsu, Japan), $10 \mu \mathrm{M}$ of each primer, $10.5 \mu \mathrm{L}$ of distilled water, and $1 \mu \mathrm{L}$ of the template DNA. All of the samples were amplified in triplicate. The negative controls without the template DNA were included for each PCR run. Reaction conditions for amplifying $16 \mathrm{~S}$ rDNA and $m c y D$ were as follows: $95{ }^{\circ} \mathrm{C}$ for $2 \mathrm{~min}$, followed by 40 cycles of $95{ }^{\circ} \mathrm{C}$ for $30 \mathrm{~s}, 55^{\circ} \mathrm{C}$ for $30 \mathrm{~s}$, and $72{ }^{\circ} \mathrm{C}$ for $30 \mathrm{~s}$. The melting temperature for the real-time PCR products was determined using the manufacturer's software.

\subsection{Statistical Analysis}

The relationships between the Microcystis genotypes and MC production as well as the environmental factors were assessed by Pearson correlations. To obtain the significant factors that explained the occurrences of the Microcystis genotypes and MC production, stepwise multiple regressions were conducted. All of the environmental variables, including $\mathrm{TP}, \mathrm{TN}, \mathrm{NH}_{4}{ }^{+}-\mathrm{N}, \mathrm{NO}_{3}{ }^{-}-\mathrm{N}$, $\mathrm{NO}_{2}{ }^{-}-\mathrm{N}, \mathrm{PO}_{4}{ }^{3-}-\mathrm{P}, \mathrm{DOC}, \mathrm{DIC}$, temperature, $\mathrm{pH}, \mathrm{DO}$, conductivity, water depth and Secchi depth, were included in the stepwise multiple linear regression analyses. Environmental variables, except $\mathrm{pH}$, were $\log _{10}(x+1)$ transformed before analysis to meet the conditions of normality and homogeneity of variance in the residuals. The variance inflation factor (VIF) was used to test the colinearity among variables, and variables with a VIF value of greater than 10 were considered to be autocorrelated with the other(s). The $\mathrm{R}^{2}$ value was used to identify the best model, and variables within the stepwise multiple regressions model were deemed significant at a P-value of less than 0.05. All of the statistical analyses were conducted using SPSS16.0 software for Windows (SPSS Inc., Chicago, IL, USA). Additionally, the Kruskal-Wallis nonparametric test was used to determine the differences between the different sampling sites during the bloom in the lake.

\section{Conclusions}

Environmental variables that affect Microcystis population dynamics and MC production were examined in the large, shallow, eutrophic Lake Chaohu. The results of our study demonstrated that total phosphorus, water temperature, and dissolved inorganic carbon were key variables influencing 
Microcystis dynamics and MC distribution across spatial and temporal scales. It is clear that eutrophication coupled with global warming can lead to more frequent toxic blooms and greater concentrations of MC. However, rising $\mathrm{CO}_{2}$ levels may suppress toxic Microcystis abundance and MC concentrations in the future. Considering the full complexity of aquatic ecosystems, changes in multiple environmental variables will not occur independent of each other, but rather simultaneously. This highlights the need for further field research to obtain a better understanding of the synergistic effects of temperature, $\mathrm{CO}_{2}$ and nutrients on the severity and toxicity of Microcystis blooms. Such information is important for monitoring and predicting the potential health risks associated with toxic Microcystis blooms, which fluctuate in response to both eutrophication and climate change. Moreover, effective management strategies can be implemented to prevent the further deterioration of the water quality in Lake Chaohu and elsewhere.

\section{Supplementary Materials}

Supplementary materials can be accessed at: http://www.mdpi.com/2072-6651/6/12/3238/s1.

\section{Acknowledgments}

This work was supported by grants from the Major Science and Technology Program for Water Pollution Control and Treatment (2012ZX07103-002), the National Natural Science Foundation of China (31200353, 31200296) and the frontier project of Nanjing Institute of Geography and Limnology, CAS (NIGLAS2012135010). We thank Dr. Fengwen Wang and Dr. Qi Huang for their kindly help in english polishing and map making.

\section{Author Contributions}

Li Yu, Fanxiang Kong and Zhen Yang conceived and designed the experiments; Li Yu performed the experiments and wrote the paper; Min Zhang and Xiaoli Shi modified the paper; Mingyong Du contributed materials and made the interpolation pictures.

\section{Conflicts of Interest}

The authors declare no conflict of interest.

\section{References}

1. Paerl, H.W.; Huisman, J. Climate change: A catalyst for global expansion of harmful cyanobacterial blooms. Env. Microbiol. Rep. 2009, 1, 27-37.

2. Ouellette, A.J.A.; Wilhelm, S.W. Toxic cyanobacteria: The evolving molecular toolbox. Front. Ecol. Environ. 2003, 1, 359-366.

3. Ye, W.; Liu, X.; Tan, J.; Li, D.; Yang, H. Diversity and dynamics of microcystin-Producing cyanobacteria in China's third largest lake, lake taihu. Harmful Algae 2009, 8, 637-644.

4. Falconer, I.R.; Beresford, A.M.; Runnegar, M.T. Evidence of liver damage by toxin from a bloom of the blue-green alga, Microcystis aeruginosa. Med. J. Aust. 1983, 1, 511-514. 
5. Carmichael, W.W. Cyanobacteria secondary metabolites-The cyanotoxins. J. Appl. Bacteriol. 1992, 72, 445-459.

6. Welker, M.; von Döhren, H. Cyanobacterial peptides-nature's own combinatorial biosynthesis. FEMS Microbiol. Rev. 2006, 30, 530-563.

7. Chorus, I.; Bartram, J. Toxic Cyanobacteria in Water: A Guide to Their Public Health Consequences, Monitoring and Management; World Health Organization, St Edmundsbury Press: Bury St Edmunds, Suffolk, UK, 1999.

8. Bartram, J.; Chorus, I. Toxic Cyanobacteria in Water: A Guide to Their Public Health Consequences, Monitoring and Management; CRC Press: Boca Raton, FL, USA, 2002.

9. Carmichael, W.W.; Falconer, I.R. Diseases related to freshwater blue-green algal toxins, and control measures. In Algal Toxins in Seafood and Drinking Water; Falconer, I.R., Ed.; Academic Press: New York, NY, USA, 1993; pp. 187-209.

10. Fleming, L.E.; Rivero, C.; Burns, J.; Williams, C.; Bean, J.A.; Shea, K.A.; Stinn, J. Blue green algal (cyanobacterial) toxins, surface drinking water, and liver cancer in florida. Harmful Algae 2002, 1, 157-168.

11. Paerl, H. Nutrient and other environmental controls of harmful cyanobacterial blooms along the freshwater-marine continuum. In Cyanobacterial Harmful Algal Blooms: State of the Science and Research Needs; Springer: New York, NY, USA, 2008; pp. 217-237.

12. Carmichael, W.W. A status Report of Planktonic Cyanobacteria (Blue-Green Algae) and Their Toxins; EPA/600/R-92/079; United States Environmental Protection Agency: Cincinnati, OH, USA, 1992.

13. Kardinaal, W.E.A.; Janse, I.; Kamst-van Agterveld, M.; Meima, M.; Snoek, J.; Mur, L.R.; Huisman, J.; Zwart, G.; Visser, P.M. Microcystis genotype succession in relation to microcystin concentrations in freshwater lakes. Aquat. Microb. Ecol. 2007, 48, 1-12.

14. Ohtake, A.; Shirai, M.; Aida, T.; Mori, N.; Harada, K.; Matsuura, K.; Suzuki, M.; Nakano, M. Toxicity of microcystis species isolated from natural blooms and purification of the toxin. Appl. Environ. Microbiol. 1989, 55, 3202-3207.

15. Welker, M.; von Döhren, H.; Täuscher, H.; Steinberg, C.E.; Erhard, M. Toxic microcystis in shallow lake müggelsee (germany)—Dynamics, distribution, diversity. Arch. Hydrobiol. 2003, 157, 227-248.

16. Paerl, H.W.; Huisman, J. Blooms like it hot. Science 2008, 320, 57-58.

17. Davis, T.W.; Berry, D.L.; Boyer, G.L.; Gobler, C.J. The effects of temperature and nutrients on the growth and dynamics of toxic and non-toxic strains of Microcystis during cyanobacteria blooms. Harmful Algae 2009, 8, 715-725.

18. Kardinaal, W.E.A.; Visser, P.M. Dynamics of cyanobacterial toxins. In Harmful Cyanobacteria Aquatic Ecology Series; Springer: Dordrecht, The Netherlands, 2005; pp. 41-64.

19. Yoshida, M.; Yoshida, T.; Takashima, Y.; Hosoda, N.; Hiroishi, S. Dynamics of microcystin-producing and non-microcystin-producing microcystis populations is correlated with nitrate concentration in a japanese lake. FEMS Microbiol. Lett. 2007, 266, 49-53.

20. Tillett, D.; Parker, D.L.; Neilan, B.A. Detection of toxigenicity by a probe for the microcystin synthetase a gene (mcya) of the cyanobacterial genus microcystis: Comparison of toxicities with 16s rrna and phycocyanin operon (phycocyanin intergenic spacer) phylogenies. Appl. Environ. Microbiol. 2001, 67, 2810-2818. 
21. Vaitomaa, J.; Rantala, A.; Halinen, K.; Rouhiainen, L.; Tallberg, P.; Mokelke, L.; Sivonen, K. Quantitative real-time PCR for determination of microcystin synthetase e copy numbers for microcystis and anabaena in lakes. Appl. Environ. Microbiol. 2003, 69, 7289-7297.

22. Rinta-Kanto, J.M.; Ouellette, A.J.A.; Boyer, G.L.; Twiss, M.R.; Bridgeman, T.B.; Wilhelm, S. Quantification of toxic microcystis spp. During the 2003 and 2004 blooms in western lake erie using quantitative real-time pcr. Environ. Sci. Technol. 2005, 39, 4198-4205.

23. Pimentel, J.S.M.; Giani, A. Estimating toxic cyanobacteria in a brazilian reservoir by quantitative real-time pcr, based on the microcystin synthetase d gene. J. Appl. Phycol. 2013, 25, 1545-1554.

24. Rinta-Kanto, J.M.; Konopko, E.A.; DeBruyn, J.M.; Bourbonniere, R.A.; Boyer, G.L.; Wilhelm, S.W. Lake Erie Microcystis: Relationship between microcystin production, dynamics of genotypes and environmental parameters in a large lake. Harmful Algae 2009, 8, 665-673.

25. Conradie, K.R.; Barnard, S. The dynamics of toxic microcystis strains and microcystin production in two hypertrofic south african reservoirs. Harmful Algae 2012, 20, 1-10.

26. Falconer, I.R. Is there a human health hazard from microcystins in the drinking water supply? Acta Hydroch. Hydrob. 2005, 33, 64-71.

27. Krüger, T.; Wiegand, C.; Kun, L.; Luckas, B.; Pflugmacher, S. More and more toxins around-analysis of cyanobacterial strains isolated from lake chao (Anhui province, China). Toxicon 2010, 56, $1520-1524$.

28. Krüger, T.; Hölzel, N.; Luckas, B. Influence of cultivation parameters on growth and microcystin production of Microcystis aeruginosa (cyanophyceae) isolated from Lake Chao (China). Microbial. Ecol. 2012, 63, 199-209.

29. Jiang, Y.J.; He, W.; Liu, W.X.; Qin, N.; Ouyang, H.L.; Wang, Q.M.; Kong, X.Z.; He, Q.S.; Yang, C.; Yang, B. The seasonal and spatial variations of phytoplankton community and their correlation with environmental factors in a large eutrophic chinese lake (Lake Chaohu). Ecol. Indic. 2014, 40, 58-67.

30. Jiang, X.; Wang, S.; Zhong, L.; Jin, X.; Sun, S. Seasonal variation characteristics of algae biomass in Chaohu Lake. J. Environ. Sci. 2010, 31, 2056-2062.

31. Yang, H.; Xie, P.; Xu, J.; Zheng, L.; Deng, D.; Zhou, Q.; Wu, S. Seasonal variation of microcystin concentration in Lake Chaohu, a shallow subtropical lake in the people's republic of China. Bull. Environ. Contam. Toxicol. 2006, 77, 367-374.

32. Zurawell, R.W.; Chen, H.R.; Burke, J.M.; Prepas, E.E. Hepatotoxic cyanobacteria: A review of the biological importance of microcystins in freshwater environments. J. Toxicol. Environ. Health B 2005, 8, 1-37.

33. Kardinaal, W.E.A.; Tonk, L.; Janse, I.; Hol, S.; Slot, P.; Huisman, J.; Visser, P.M. Competition for light between toxic and nontoxic strains of the harmful cyanobacterium Microcystis. Appl. Environ. Microbiol. 2007, 73, 2939-2946.

34. Falconer, I.R. An overview of problems caused by toxic blue-green algae (cyanobacteria) in drinking and recreational water. Environ. Toxicol. 1999, 14, 5-12.

35. Xu, F.L.; Tao, S.; Dawson, R.; Xu, Z. The distributions and effects of nutrients in the sediments of a shallow eutrophic chinese lake. Hydrobiologia 2003, 492, 85-93. 
36. Cai, Y.F. Comparative Study of Composition and Dynamics of Cyanobacteria and Their Driving Factors in Lake Taihu and Lake Chaohu; Nanjing Institute of Geography and Limnology Chinese Academy of Sciences: Nanjing, China, 2012.

37. Kurmayer, R.; Kutzenberger, T. Application of real-time PCR for quantification of microcystin genotypes in a population of the toxic cyanobacterium Microcystis sp. Appl. Environ. Microbiol. 2003, 69, 6723-6730.

38. Hotto, A.M.; Satchwell, M.F.; Berry, D.L.; Gobler, C.J.; Boyer, G.L. Spatial and temporal diversity of microcystins and microcystin-producing genotypes in oneida lake, ny. Harmful Algae 2008, 7, 671-681.

39. Yu, T.; Xie, P.; Dai, M.; Liang, G.D. Determinations of MC-LR and (Dha7) MC-LR concentrations and physicochemical properties by liquid chromatography-tandem mass spectrometry. Bull. Environ. Contam. Toxicol. 2009, 83, 757-760.

40. Chen, W.; Song, L.R.; Ou, D.Y.; Gan, N.Q. Chronic toxicity and responses of several important enzymes in Daphnia magna on exposure to sublethal microcystin-LR. Environ. Toxicol. 2005, 20, 323-330.

41. Chen, J.; Xie, P. Tissue distributions and seasonal dynamics of the hepatotoxic microcystins-LR and-RR in two freshwater shrimps, Palaemon modestus and Macrobrachium nipponensis, from a large shallow, eutrophic lake of the subtropical China. Toxicon 2005, 45, 615-625.

42. Xie, L.Q.; Xie, P.; Guo, L.G.; Li, L.; Miyabara, Y.; Park, H.D. Organ distribution and bioaccumulation of microcystins in freshwater fish at different trophic levels from the eutrophic lake Chaohu, China. Environ. Toxicol. 2005, 20, 293-300.

43. Chen, J.; Xie, P. Accumulation of hepatotoxic microcystins in freshwater mussels, aquatic insect larvae and oligochaetes in a large, shallow eutrophic lake (Lake Chaohu) of subtropical China. Fresenius Environ. Bull. 2008, 17, 849-854.

44. Chen, J.; Xie, P.; Li, L.; Xu, J. First identification of the hepatotoxic microcystins in the serum of a chronically exposed human population together with indication of hepatocellular damage. Toxicol. Sci. 2009, 108, 81-89.

45. Giani, A.; Bird, D.; Prairie, Y.; Lawrence, J. Empirical study of cyanobacterial toxicity along a trophic gradient of lakes. Can. J. Fish. Aquat. Sci. 2005, 62, 2100-2109.

46. Graham, J.L.; Jones, J.R.; Jones, S.B.; Downing, J.A.; Clevenger, T.E. Environmental factors influencing microcystin distribution and concentration in the midwestern united states. Water Res. 2004, 38, 4395-4404.

47. Joung, S.H.; Oh, H.M.; Ko, S.R.; Ahn, C.Y. Correlations between environmental factors and toxic and non-toxic Microcystis dynamics during bloom in daechung reservoir, korea. Harmful Algae 2011, 10, 188-193.

48. Boopathi, T.; Ki, J.S. Impact of environmental factors on the regulation of cyanotoxin production. Toxins 2014, 6, 1951-1978.

49. Vézie, C.; Rapala, J.; Vaitomaa, J.; Seitsonen, J.; Sivonen, K. Effect of nitrogen and phosphorus on growth of toxic and nontoxic Microcystis strains and on intracellular microcystin concentrations. Microb. Ecol. 2002, 43, 443-454. 
50. Tillett, D.; Dittmann, E.; Erhard, M.; von Döhren, H.; Börner, T.; Neilan, B.A. Structural organization of microcystin biosynthesis in Microcystis aeruginosa PCC7806: An integrated peptide-polyketide synthetase system. Chem.Biol. 2000, 7, 753-764.

51. Hesse, K.; Kohl, J. Effects of light and nutrient supply on growth and microcystin concentration of different strains of Microcystis aeruginosa. In Cyanotoxins: Occurrence, Effects, Controlling Factors; Chorus, I., Ed.; Springer: Heidelberg/Berlin, Germany, 2001.

52. Orr, P.T.; Jones, G.J. Relationship between microcystin production and cell division rates in nitrogen-limited Microcystis aeruginosa cultures. Limnol. Oceanogr. 1998, 43, 1604-1614.

53. Gobler, C.; Davis, T.W.; Coyne, K.; Boyer, G. Interactive influences of nutrient loading, zooplankton grazing, and microcystin synthetase gene expression on cyanobacterial bloom dynamics in a eutrophic new york lake. Harmful Algae 2007, 6, 119-133.

54. Davis, T.W.; Harke, M.J.; Marcoval, M.; Goleski, J.; Orano-Dawson, C.; Berry, D.L.; Gobler, C.J. Effects of nitrogenous compounds and phosphorus on the growth of toxic and non-toxic strains of Microcystis during cyanobacterial blooms. Aquat. Microb. Ecol. 2010, 61, 149-162.

55. Te, S.H.; Gin, K.Y.H. The dynamics of cyanobacteria and microcystin production in a tropical reservoir of singapore. Harmful Algae 2011, 10, 319-329.

56. Otten, T.G; Xu, H.; Qin, B.; Zhu, G.; Paerl, H. Spatiotemporal patterns and ecophysiology of toxigenic microcystis blooms in lake taihu, China: Implications for water quality management. Environ. Sci. Technol. 2012, 46, 3480-3488.

57. Raven, J.A.; Geider, R.J. Temperature and algal growth. New Phytol. 1988, 110, 441-461.

58. Reynolds, C.S.; Usher, M.; Saunders, D.; Dobson, A.; Peet, R.; Adam, P.; Birks, H.; Gustafsson, L.; McNeely, J.; Paine, R. Ecology of Phytoplankton; Cambridge University Press: Cambridge, UK, 2006; Volume 535.

59. Joehnk, K.D.; Huisman, J.E.F.; Sharples, J.; Sommeijer, B.; Visser, P.M.; Stroom, J.M. Summer heatwaves promote blooms of harmful cyanobacteria. Glob. Chang. Biol. 2008, 14, 495-512.

60. O’Neil, J.M.; Davis, T.W.; Burford, M.A.; Gobler, C.J. The rise of harmful cyanobacteria blooms: The potential roles of eutrophication and climate change. Harmful Algae 2012, 14, 313-334.

61. Lee, S.J.; Jang, M.H.; Kim, H.S.; Yoon, B.D.; Oh, H.M. Variation of microcystin content of Microcystis aeruginosa relative to medium N: P ratio and growth stage. J. Appl. Microbiol. 2000, 89, 323-329.

62. Li, D.; Yu, Y.; Yang, Z.; Kong, F.; Zhang, T.; Tang, S. The dynamics of toxic and nontoxic Microcystis during bloom in the large shallow lake, Lake taihu, China. Environ. Monit. Assess. 2014, 186, 3053-3062.

63. Paerl, H.W. Nuisance phytoplankton blooms in coastal, estuarine, and inland waters. Limnol. Oceanogr. 1988, 33, 823-847.

64. Shapiro, J. The role of carbon dioxide in the initiation and maintenance of blue-green dominance in lakes. Freshw. Biol. 1997, 37, 307-323.

65. Raven, J.A.; Giordano, M.; Beardall, J.; Maberly, S.C. Algal evolution in relation to atmospheric $\mathrm{CO}_{2}$ : Carboxylases, carbon-concentrating mechanisms and carbon oxidation cycles. Philos. Trans. R. Soc. B 2012, 367, 493-507.

66. Giordano, M.; Beardall, J.; Raven, J.A. Co 2 concentrating mechanisms in algae: Mechanisms, environmental modulation, and evolution. Annu. Rev. Plant Biol. 2005, 56, 99-131. 
67. Okello, W.; Kurmayer, R. Seasonal development of cyanobacteria and microcystin production in ugandan freshwater lakes. Lakes Reserv. Res. Manag. 2011, 16, 123-135.

68. Nakano, S.I.; Murabe, A.; Tsujimura, S.; Hayakawa, K.; Nakajima, T.; Kumagai, M.; Jiao, C.; Kawabata, Z.I. Dominance of Microcystis with special reference to carbon availability in Lake water. Microbes Environ. 2003, 18, 38-42.

69. Qiu, B.; Gao, K. Effects of $\mathrm{CO}_{2}$ enrichment on the bloom-forming cyanobacterium Microcystis aeruginosa (cyanophyceae): Physiological responses and relationships with the availability of dissolved inorganic carbon. J. Phycol. 2002, 38, 721-729.

70. Jähnichen, S.; Ihle, T.; Petzoldt, T.; Benndorf, J. Impact of inorganic carbon availability on microcystin production by Microcystis aeruginosa PCC 7806. Appl. Eenviron. Microbiol. 2007, 73, 6994-7002.

71. Jähnichen, S.; Petzoldt T.; Benndorf J. Evidence for control of microcystin dynamics in Bautzen Reservoir (germany) by cyanobacterial population growth rates and dissolved inorganic carbon. Arch. Hydrobiol. 2001, 150, 177-196.

72. Poste, A.E.; Hecky, R.E; Guildford, S.J. Phosphorus enrichment and carbon depletion contribute to high Microcystis biomass and microcystin concentrations in Ugandan lakes. Limnol. Oceanogr. 2013, 58, 1075-1088.

73. Van de Waal, D.B.; Verspagen, J.M.; Finke, J.F.; Vournazou, V.; Immers, A.K.; Kardinaal, W.E.; Tonk, L.; Becker, S.; van Donk, E.; Visser, P.M.; et al. Reversal in competitive dominance of a toxic versus non-toxic cyanobacterium in response to rising $\mathrm{CO}_{2}$. ISME J. 2011, 5, 1438-1450.

74. Lorenzen, C.J. Determination of chlorophyll and pheopigments: Spectrophotometric equations. Limnol. Oceanogr. 1967, 12, 343-346.

75. Barco, M.; Lawton, L.A.; Rivera, J.; Caixach, J. Optimization of intracellular microcystin extraction for their subsequent analysis by high-performance liquid chromatography. J. Chromatogr. A 2005, 1074, 23-30.

76. Tillett, D.; Neilan, B.A. Xanthogenate nucleic acid isolation from cultured and environmental cyanobacteria. J. Phycol. 2000, 36, 251-258.

77. Neilan, B.A.; Jacobs, D.; Blackall, L.L.; Hawkins, P.R.; Cox, P.T.; Goodman, A.E. Rrna sequences and evolutionary relationships among toxic and nontoxic cyanobacteria of the genus Microcystis. Int. J. Syst. Bacteriol. 1997, 47, 693-697.

78. Kaebernick, M.; Neilan, B.A.; Börner, T.; Dittmann, E. Light and the transcriptional response of the microcystin biosynthesis gene cluster. Appl. Environ. Microbiol. 2000, 66, 3387-3392.

(C) 2014 by the authors; licensee MDPI, Basel, Switzerland. This article is an open access article distributed under the terms and conditions of the Creative Commons Attribution license (http://creativecommons.org/licenses/by/4.0/). 